Editorial

\title{
Sociedade Brasileira de Transplante de Medula Óssea: Falando alto e em bom tom
}

Daniel G. Tabak

A Sociedade Brasileira de Transplante de Medula Óssea (SBTMO) foi fundada em 15 de abril de 1996, objetivando fortalecer a especialidade em nosso país. Neste sentido, a SBTMO não veio competir com a Associação Brasileira de Transplante de Órgãos (ABTO), mas sim ressaltar os aspectos importantes que tornam a medula óssea um tecido único para transplante, uma doação que sempre se estabelece em vida, com características próprias bem definidas e que precisam ser valorizadas. Marchamos juntos, entretanto, em várias avenidas, lutando contra vários obstáculos no desenvolvimento de programas de alta complexidade em um ambiente ainda pouco favorável e inóspito.

"O transplante de medula óssea começou certo no Brasil...". Este registro do professor Ricardo Pasquini, coordenador do Centro de Transplante de Medula Ó ssea da Universidade Federal do Paraná e primeiro presidente da SBTMO, é uma discrição fiel dos nossos princípios: ética fundamentada em sólidas bases científicas. Ao longo dos últimos vinte anos e com mais de 2000 procedimentos realizados, podemos afirmar que estamos cumprindo o nosso papel junto à sociedade. Os resultados são semelhantes obtidos nos centros mais desenvolvidos do exterior e constituem motivo de orgulho para todos que se dedicam intensamente ao cuidado destes pacientes.

Os esforços nesse sentido se estendem do norte ao sul do país. Hoje, existem 17 centros tranplantadores credenciados pelo Ministério da Saúde, infelizmente ainda concentrados nas regiões mais desenvolvidas do Brasil. Entretanto, já observamos alguns esforços, embora ainda isolados, em alguns centros do nordeste. Nos últimos seis meses foram credenciados novos centros em São Paulo, em Campinas, em São José do Rio Preto, em Goiânia e Florianópolis. Com eles, surgem novas perspectivas de desenvolvimento científico, intercâmbio de idéias e profissionais e, mais significativamente, novas oportunidades de tratamento para nossa população.

Recentemente observamos uma preocupação maior do Ministério da Saúde em normatizar a política de transplante de medula óssea no país. Através da portaria 3761 de 20 de outubro de 1998, foi atribuída ao Instituto Nacional de Câncer a responsabilidade pela assessoria técnica deste projeto. A SBTMO vem contribuindo significativamente nesta empreitada, impedindo que a estruturação de um programa nacional fosse devolvida como uma atividade isolada, burocratizada e sem expressão científica. Reunidos os seus membros em várias ocasiões, os esforços foram coroados com a publicação em 13 de outubro de 1999 da portaria 1217. Trata-se de um decreto ímpar que precisa ainda ser aprimorado. Entretanto, ele regulamenta as várias indicações para 0 transplante de medula óssea, normatiza as condições para a assistência e estabelece as condições iniciais para a viabilização do programa de transplantes utilizando doadores não aparentados. A portaria também tornará possível a expansão do registro nacional de

Chefe do CEMO, Instituto Nacional do Câncer

Presidente da Sociedade Brasileira de Transplante de Medula Óssea 
doadores (RED OME) através de um reembolso justo para a execução dos estudos imunogenéticos. Com os novos códigos, foi afastada a sombra do "custo proibitivo" para identificar, coletar e transportar células de doadores dos centros internacionais para pacientes a serem transplantados aqui no Brasil. De forma ainda mais significativa, o Ministério da Saúde identifica a SBTMO como parceira no cadastramento de novos centros, definições de novos protocolos de tratamento e novas estratégias operacionais. Reconhecendo ainda a obrigatoriedade de um sistema ágil de financiamento para garantir a continuidade do processo, foram alocados recursos do FAECFundo de Ações Estratégicas e Compensação para a manutenção do programa.

Existem ainda vários pontos a serem explorados. 0 transplante de medula óssea continua inserido na legislação que lida com os transplantes de forma geral. A portaria 1217 constitui 0 primeiro passo para 0 reconhecimento da especificidade do transplante de medula óssea: as complicações apresentadas por nossos pacientes são muitos freqüentes e resultam em reinternações prolongadas. No entanto, o ressarcimento para as instituições encontra-se extremamente defasado e vários procedimentos não estão contemplados nas tabelas vigentes. Obtivemos recentemente o compromisso da Secretaria de Assistência à Saúde/MS de rever estes valores, estratégia crítica para garantir a continuidade da assistência nos vários centros.

Estabelecemos uma reunião anual que vem adquirindo expressão crescente no cenário nacional e internacional, reunindo especialistas de elevado conhecimento e criando o fórum correto para discussão de problemas técnicocientíficos bem como as estratégias para atingir os nossos objetivos. O local escolhido foi Curitiba, berço do transplante de medula óssea no Brasil.

Com este número da Revista Brasileira de Hematologia e Hemoterapia, inicia-se uma nova era para a SBTMO. Os membros da nossa sociedade são extremamente gratos a Sociedade Brasileira de Hematologia e Hemoterapia por esta oportunidade, tornando este 0 canal oficial de nossas comunicações. Esperamos receber contribuições de todos aqueles que batalham pelo desenvolvimento do transplante de medula óssea no Brasil, tornando a nossa voz cada vez mais clara, na luta por nossos ideais. 